\title{
Evaluation of the repair of diaphyseal fracture of femoral bone using bone marrow mesenchymal stem cells in nicotine-bearing rat
}

\author{
Riahi $\mathrm{M}^{1}$, Parivar $\mathrm{K}^{1}$, Baharara $\mathrm{J}^{2}$, Zandi $\mathrm{R}^{3}$ \\ Department of Biology, School of Basic Sciences, Science and Research Branch, Islamic Azad University, \\ Tehran, Iran. parivarkaze@gmail.com
}

\begin{abstract}
OBJECTIVE: Following bone fractures during accidents, some patients suffer from poor repair of bone fractures and subsequent aesthetic and psychological problems. One of the treatments is based on transplantation of stem cells (seeded on scaffolds) to the lesion site. Bone marrow stromal cells (BMSCs) are multivalent stem cells which are able to reproduce and differentiate into osteogenic cells. The objective of this study was to evaluate the treatment of bone fractures by means of transplantation of the latter cells in rats.

METHODS: In this study, the therapeutic effect of mesenchymal stem cells from bone marrow adipocytes was evaluated in bone fractures. BMSCs were isolated from rat femur. Two sources of differentiated and non-differentiated osteocyte cells were provided and mixed with collagen in order to be transferred to animals divided in three main groups of model: nicotine, non-nicotine and control groups. After four weeks, the repair of the fracture that had been inflicted by a 2-mm drill into the diaphyseal region of the femoral bone was investigated by radiographic tests and histopathologic staining.

RESULTS: The radiographic results as well as those of histopathologic staining showed that osteogenesis was more intensive in the non-nicotine group than in the nicotine group with differentiated and non-differentiated osteocyte cells.

CONCLUSION: The transplantation of differentiated BMSCs to a bone lesion affected the repair of bone fractures while the nicotine agent played an important role in delaying the bone regeneration (Tab. 1, Fig. 8, Ref. 31). Text in PDF www.elis.sk.

KEY WORDS: bone marrow mesenchymal stem cell, nicotine, rat, bone fracture regeneration.
\end{abstract}

\section{Introduction}

One of the most common abnormalities in bone fractures is the slow and imperfect repair. Bone density reduces with age and makes bones prone to fractures. Imperfect repair brings about disabilities, which incur high cost for both the individual and society. Due to the relative limitation of repair in the above conditions, researchers try to find a suitable treatment for these patients. There are several modes of therapy for quick repair of bone fractures. One of these modes is cell therapy. In order to gain the best outcome from cell transplantation, the cells required for this propose should have features such as easy access, rapid division in the culture medium, immunology that is neutral or synchronized with

\footnotetext{
${ }^{1}$ Department of Biology, School of Basic Sciences, Science and Research Branch, Islamic Azad University, Tehran, Iran, ${ }^{2}$ Biology Department \& Research Center for Animal, Development Applied Biology, Mashhad Branch, Islamic Azad University, Mashhad, Iran, and ${ }^{3}$ Taleghani Hospital, Shahid Beheshti University of Medical Sciences, Tehran, Iran

Address for correspondence: K. Parivar, Department of Biology, School of Basic Science, Science and Research Branch, Islamic Azad University, Tehran, Iran.

Phone: +989121304550
}

recipient tissue, capability of long-term survival and compatibility with host tissue. According to these characteristics, bone marrow stromal cells (BMSCs) seem to be suitable alternatives for this purpose $(1,2)$. Mesenchymal stem cells derived from bone marrow (BMSCs), which have the potential to form different types of mesenchymal tissues, are also the cellular source for bone tissue engineering applications. From the scientific point of view, the stem cell is considered to be an undifferentiated cell with the abilities of multiplication, self-renewal, and production of different cell lines. The bone marrow is a soft tissue full of blood vessels with scaffolds of reticular strata that blood cells, adipocytes and stem cells are placed on (3-5). In this tissue, the bone marrow and reticular cells are stationary with little phagocytic potency and do not convert into blood precursors. Under laboratory conditions, the mesenchymal cells that are located in the bone marrow cavities are able to transform into a variety of other cells, including chondrocytes, osteoblasts, fibroblasts, adipocytes, endothelial cells and myocytes (6-8). The mesenchymal stem cells in the bone marrow have an extensive association with various cells such as blood vessel endothelial cells, osteoblasts, reticular cells of the red bone marrow and adipocytes $(9,10)$. This association is essential for processes such as hematopoiesis, production and maturation of defense cells, and regulation of immune response (11). It has also 
been shown that the connection between mesenchymal stem cells and these cells is through both physical and chemical mechanisms such as production and secretion of molecules and growth factors (12). Unnder normal condition, the mesenchymal stem cells in the bone marrow are in a non-differentiated state (13). The repair mechanisms activated by stem cells include the proliferation and differentiation of damaged cells, control of the programmed cell death, mobilisation of other cells from other areas affecting the repair, and control and modification of immune response in the injured area (14-16). Although the mentioned mechanisms do not fully cover the repair in the tissue, these mechanisms can be considered to be the basis for damaged tissue repair. In general, there are two main reasons for the use of mesenchymal stem cells for the therapeutic purpose, including the creation and replacement of damaged cells and secretion of factors effective in the repairment process performed by mesenchymal stem cells. The creation and replacement of damaged cells form the basis of cell therapy in restorative medicine. The secretion of factors effective in the repairment process performed by mesenchymal stem cells is considered to be the pivotal element also in many cellular processes (17). The purpose of this study was to evaluate the repair effect of mesenchymal stem cells from rat bone marrow in rat diaphyseal bone fractures.

\section{Materials and methods}

\section{Isolation and culture of mesenchymal stem cells of rat bone marrow}

In order to isolate and culture the mesenchymal stem cells of bone marrow, Wistar male rats (Rattus norvegicus; 200 to 250 g) were purchased from a laboratory of experimental animals at Baqiyatallah University of Medical Sciences (Tehran, Iran). The animals were anesthetized by inhalation of carbon dioxide. The rats were immersed in $70 \%$ alcohol, then in iodine and again in $70 \%$ alcohol to eliminate the contaminating agents on the body surface. The femur and tibia were removed from both sides and the tissues adhering to the bones were cleaned off. Next, the cleaned bones were soaked in PBS containing antibiotics, namely penicillin $(100 \mathrm{unit} / \mathrm{ml})$ and streptomycin $(100 \mathrm{mg} / \mathrm{ml})$ and placed under laminar flow. Under sterile conditions, the DMEM-Low glucose culture medium was added to $10 \mathrm{ml}$ syringes. The two ends of the bones were cut and the contents was drained by flushing method with syringes into $25-\mathrm{ml}$ cell culture flasks. Subsequently, $10 \%$ FBS, $1 \%$ Pen/Strep and finally, low-glucose DMEM were added to reach volume of $5 \mathrm{ml}$. The flasks were incubated in $5 \% \mathrm{CO}_{2}$ at $37^{\circ} \mathrm{C}$. The next day, the floating cells were washed with PBS and adherent cells were cultured for 14 days while changing the media every three days. Following 14 days, when the confluency of cells reached $80 \%$, the first sub-culture was performed using Trypsin/EDTA $2.5 \%$ solution to allow cells to grow and proliferate. Briefly, the cell culture media was removed and the cells were washed with PBS. Then the cells were incubated for 3-5 min with $0.5 \mathrm{ml}$ of $1 \mathrm{X}$ trypsin. After detaching the cells, the media containing FBS was added to the flask to neutralize the effect of trypsin. The cells were pelleted at $600 \mathrm{~g}$ for $8 \mathrm{~min}$ (1200 rpm for $7 \mathrm{~min}$ ). The pellet was resuspended in $1 \mathrm{ml}$ of new culture media. Ten microliters of the cell suspension were stained with $0.4 \%$ trypan blue and counted using Neubar glass slid under the inverted microscope. The percentage of live cells and total number of cells were obtained. Considering the ability of population growth (doubling time), the cells were transferred to other flasks with the ratio of 1 to 2 or 1 to 3 . The second passage of cells was performed in the same way.

\section{Evaluation of cell surface specific markers}

To evaluate the surface markers, the cells from the third subculture were used. The cells were detached using trypsin and resuspended in $1 \mathrm{ml}$ PBS. Then, $50 \mu \mathrm{l}$ of cell suspension containing $10^{6}$ cells was transferred to each tube of test and isotype control. The amount of $5 \mu 1$ of the CD90, CD106, CD34 and CD45 monoclonal antibodies were added to the test tubes. The amount of $5 \mu \mathrm{l}$ of IgG-FITC antibody against rat cells was added to the isotype control tube to identify and remove non-specific bonds. The tubes were placed in darkness for $30 \mathrm{~min}$ at $4{ }^{\circ} \mathrm{C}$. Then, a volume of 500 $\mu \mathrm{PBS}$ was added to the sample and washed. Cells were then fixed by $50 \mu$ of paraformaldehyde solution (the paraformaldehyde solution can be added simultaneously with the antibody) and then the fluorescence of the samples was examined by flow cytometry (18).

\section{Differentiation into osteocyte and adipocyte}

In this study, the osteocyte differentiation test was used to verify the nature mesenchymal cells and their differentiation potency. The media of the third subculture of confluent cells was changed with bone differentiation media and the cell differentiation culture was maintained for 21 days. The osteocyte differentiation media contained DMEM containing $50 \mu \mathrm{g} / \mathrm{ml}$ ascorbic acid 3-phosphate, $10 \mathrm{~nm}$ dexamethasone and $10 \mathrm{mM}$ beta-glycerol phosphate. For differentiation into cartilage, $0.5 \mathrm{ml}$ of chondrogenic media including DMEM containing $10 \mathrm{ng}$ TGF-B3 growth factor, $50 \mathrm{mg}$ ITS+premix, $10 \mathrm{ng}$ BMP-6, $3.55 \mathrm{mg}$ linoleic acid, $1.25 \mathrm{mg}$ bovine serum albumin and $2 \%$ bovine serum was added to the cell pellet at the bottom of the tube. Adipocyte differentiation was performed as follows-. The third sub-cultures of confluent cells were cultured in a 6-well plate. After covering the cells with adipogenic medium (DMEM), the media containing $10 \%$ FBS, $50 \mu \mathrm{g} / \mathrm{ml}$ ascorbic acid 2-phosphate, $100 \mathrm{~nm}$ dexamethasone and $50 \mu \mathrm{g} / \mathrm{ml}$ indomethacin were replaced. The cells grown in normal media were considered control. The cell differentiation was investigated three weeks after the beginning of the culture, using oil red and alizarin red stains.

Tab. 1. Primers specifications.

\begin{tabular}{llcc}
\hline Primer & sequence & Size (bp) & TM \\
\hline \multirow{2}{*}{ SPP1 } & F: 5'CGCAGTTCTCCTGGCTGAAT -3' & \multirow{2}{*}{ 150bp } & 59.35 \\
& R: 5'-AGTGTTTGCTGTAATGCGCC-3 ' & & 57.30 \\
\hline \multirow{2}{*}{ ALP1 } & F: 5'-GGACCCTGCCTTACCAACTC -3' & \multirow{2}{*}{$245 \mathrm{bp}$} & 61.40 \\
& R: 5'-AACTTGTCCATCTCCAGCCG -3' & & 59.35 \\
\hline \multirow{2}{*}{ BGLAP } & F: 5'-GAATAGACTCCGGCGCGCTACC -3' & \multirow{2}{*}{$229 \mathrm{bp}$} & 61.40 \\
& R: 5'-TCGAGTCCTGGAGAGTAGCC -3' & & 61.40 \\
\hline
\end{tabular}




\section{4-442}
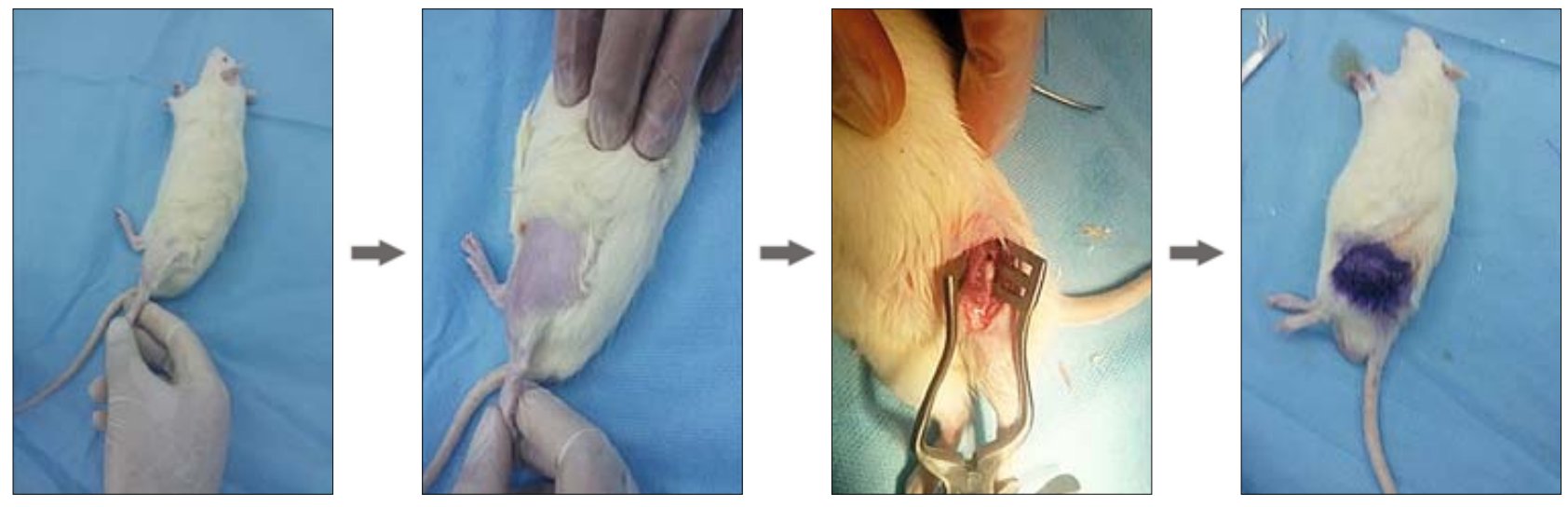

Fig. 1. Preparation and surgery of rats.
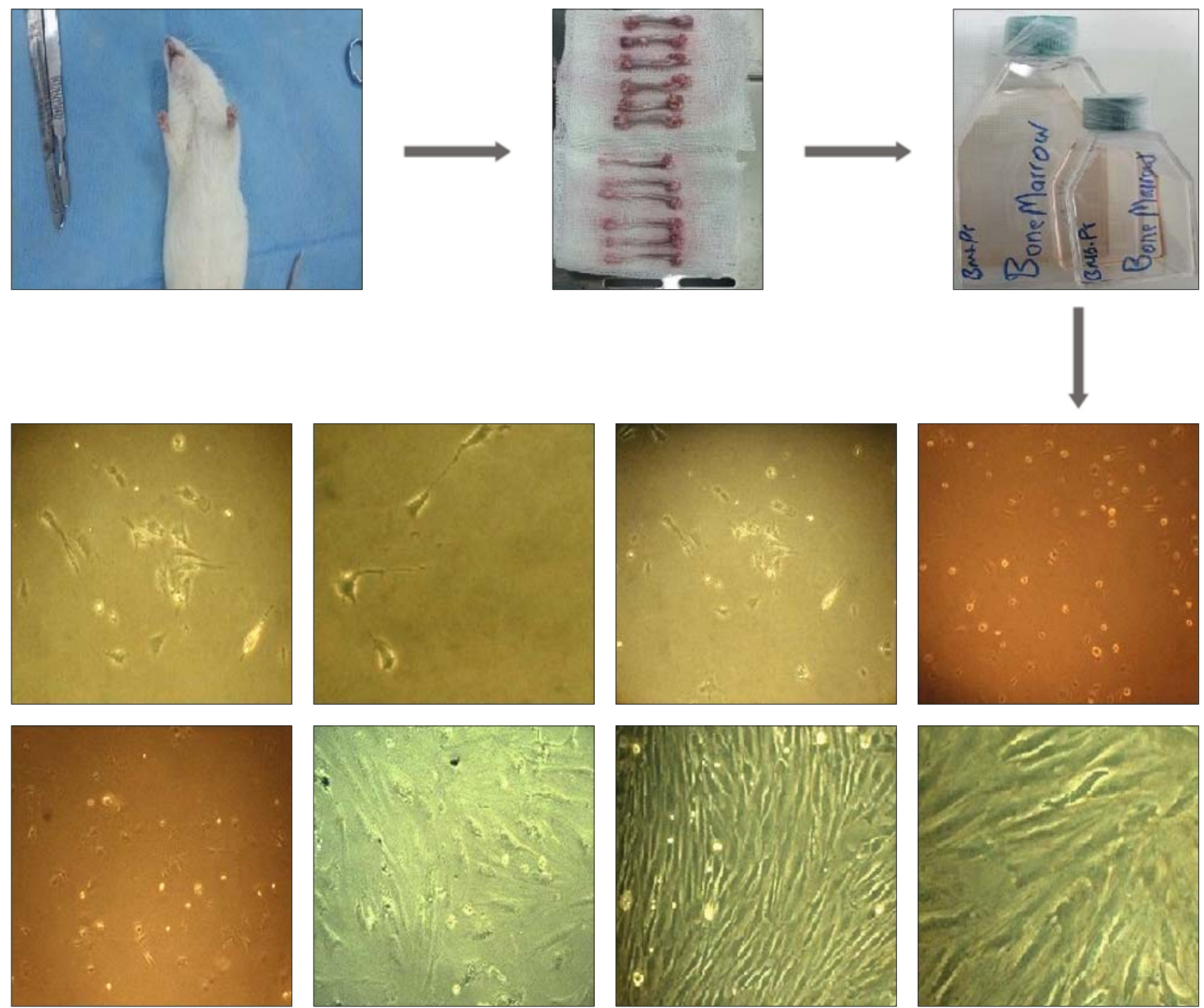

Fig. 2. The steps of femur and tibia extraction from rat, primary culture of mesenchymal cells, and subculture of mesenchymal cells in 25- and 75-ml culture flasks $(100,200$ and $400 \times)($ Scale bar: $1 \mu \mathrm{m})$. 

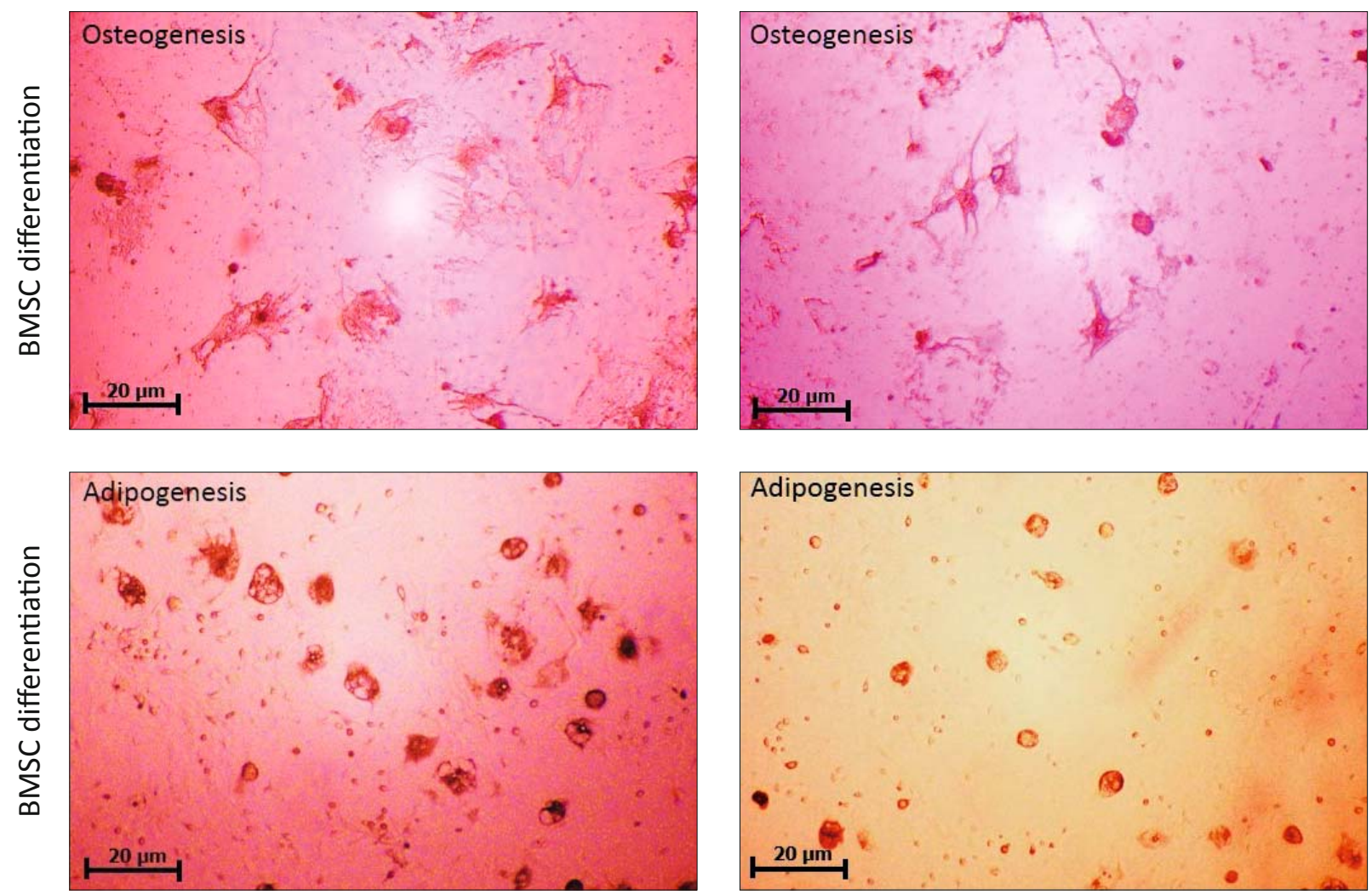

Fig. 4. BMSCs differentiation to osteocytes and adipocytes. Alizarin red and oil red staining were used for osteogenesis and adipogenesis differentiation confirmation, respectively.
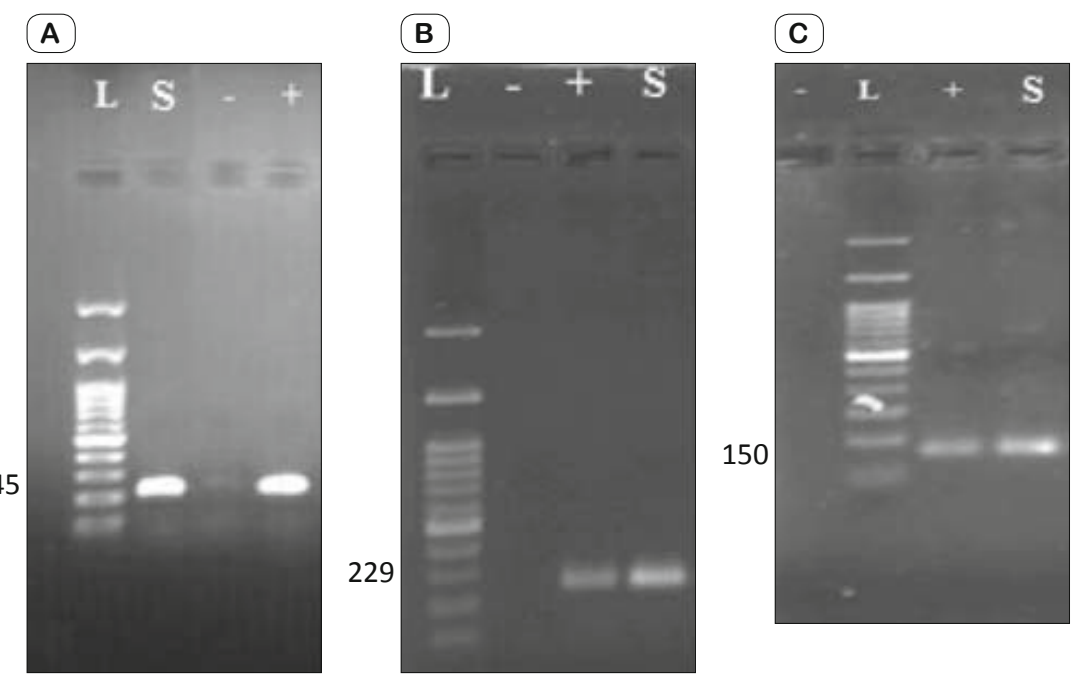

Fig. 5. Expression of alkaline phosphatase (A), osteocalcin (B), osteopontin (C) genes in the differentiation of bone marrow mesenchymal cells. L: ladder, -: negative control, +: positive control, S: bone marrow mesenchymal cells.

\section{Preparation and surgery}

All experiments were carried out according to the instructions of the Animal Ethics Committee of Baqiyatallah University of Medical Sciences. This protocol relates to the observance of the ethical principles and protection of animals used for laboratory and other scientific purposes. Type I collagen was extracted by ketamine $(90 \mathrm{mg} / \mathrm{kg})$ and xylazine $(10 \mathrm{mg} / \mathrm{kg})$ intraperitoneally. After shaving the thighs, the area was cleaned with iodine and alcohol. The hands and feet of the animals were fixed on the specified areas on the surgery bed, and then a cut was created on the skin. The fascia and muscles were cut slowly and the relevant area appeared. Then, a lesion was created using a trephine $(4 \mathrm{~mm}$ 

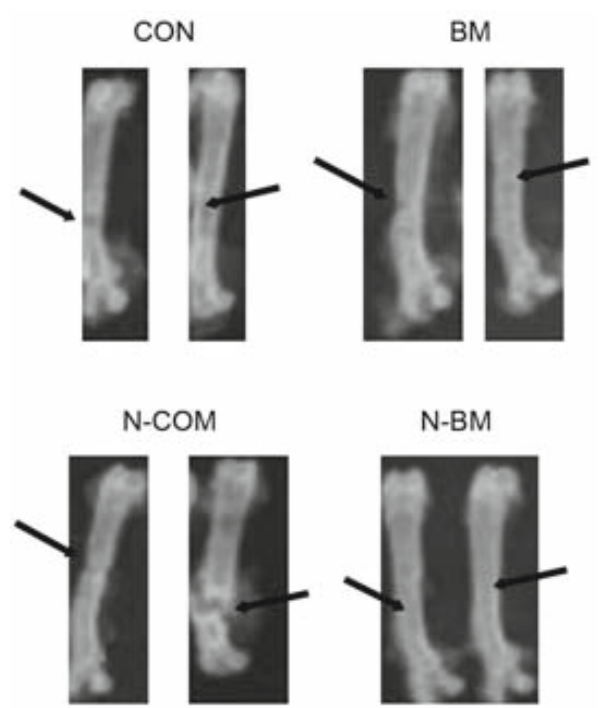

Fig. 6. Radiographic images after 4 weeks. CON: control, BM: differentiated osteocytes of BMSCs, N-CON: nicotine control, N-BM: differentiated osteocytes of BMSCs in the nicotine group.

in diameter), and the cells in each group were cemented to the critical size for bone regeneration. The differentiated osteocytes from bone marrow mesenchymal cells were injected to the control group (without nicotine) and those of nicotine model. The skins were stitched up by suture (4-0), disinfected with tetracycline spray and recovered. Then amoxicillin $(0.1 \mathrm{mg} / \mathrm{kg})$ was injected. After

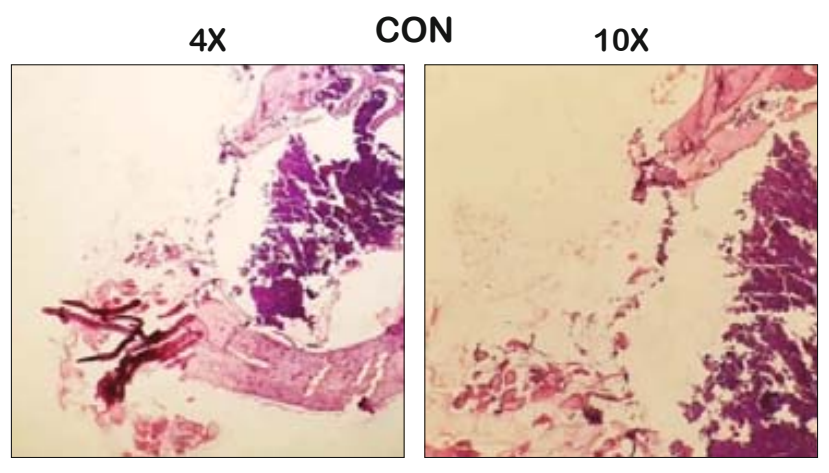

BM
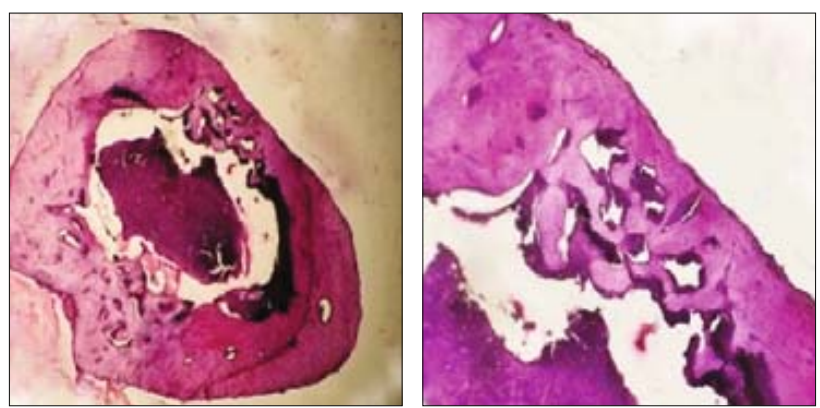

surgery, the animals were kept in a clean cage and transferred to the animal house (Fig. 1). The rats were kept inside the cage at a suitable temperature and appropriate nutrition conditions. After 4 weeks, the rats were sacrificed with a high dose of anesthesia and the specimens were removed.

\section{Radiographic examination}

Four weeks after the cell transplantation, radiographic examination of the right femoral bone was performed with a Senographe 600T Senix H.F device at a dose of $22 \mathrm{KV}$ and 9 mas. The test was performed from the anterior-posterior (AP) and lateral (Lat) views and the rate of bone formation was scored by three persons upon inspecting the images.

\section{Hematoxylin-eosin staining}

For histopathologic examination, the bones were immersed in $10 \%$ nitric acid for 2 weeks and tested with syringe tip. At the end of specified time, the samples were sent to the histopathologic laboratory, where decalcification, tissue-processing and sectioning steps ( 5 microns) were performed. The specimens were stained with hematoxylin-eosin (H\&E) and examined and photographed with a light microscope (21-23).

\section{Results}

Isolation and culture of bone mesenchymal cells

As stated in the introduction, the characteristics of mesenchymal cells such as easy isolation and proliferation when compared to other types of stem cells, and their potential for conversion
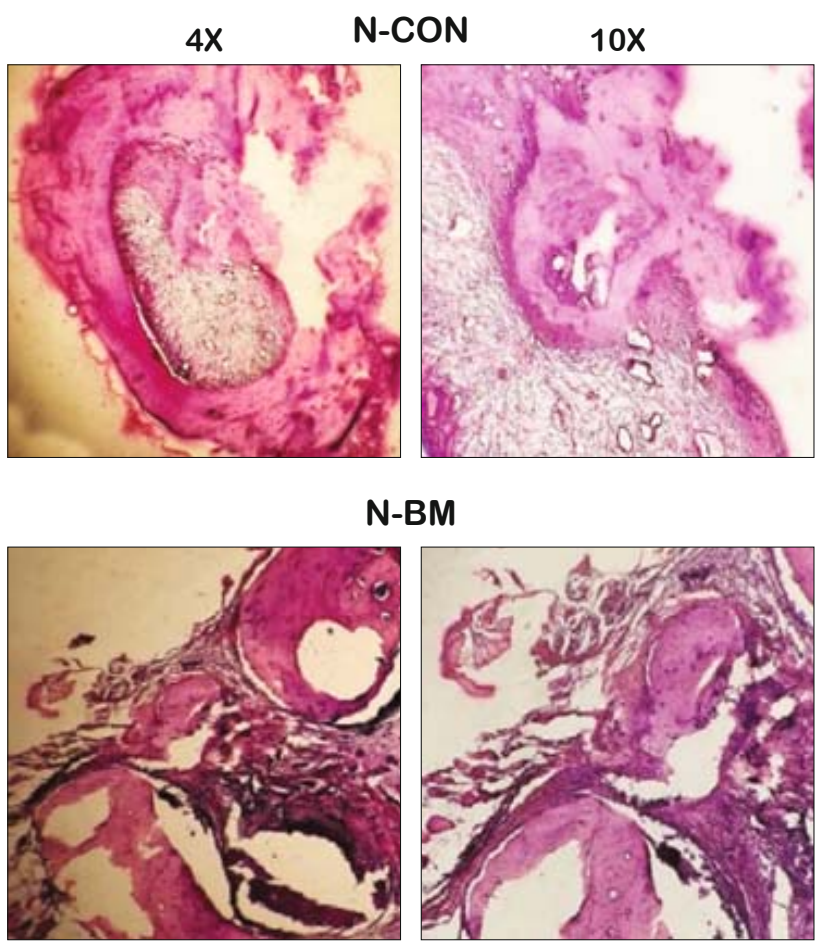

Fig. 7. Hematoxylin-eosin staining after 4 weeks. CON: control, BM: differentiated osteocytes of BMSCs, N-CON: nicotine control, N-BM: differentiated osteocytes of BMSCs in the nicotine group ( $\times 4$ and 10). 
into different types of cells led to the selection of these cells for culture and evaluation of the damaged tissue repair. For this purpose, the bone marrow mesenchymal cells isolated from rat femur and tibia were cleaned from other impurities through several steps of centrifugation with PBS and filtration. For separation of polymorphonuclears, they were added into the tube, centrifuged and then cultured. Since the mesenchymal cells typically bind to the surface, the other cells were washed out by intermittent media changes. After 4 subcultures, the cells were relatively purified and a part of them was stored and frozen (Fig. 2). Flow cytometry graphs showed that the cells with very low expression of CD34 and CD45 and high expression of CD90 and CD106 markers were mesenchymal stem cell types (Fig. 3). The mesenchymal stem cells differentiated into osteocytes and adipocytes were recognized by alizarin red and oil red, respectively. Their differentiation is shown in Figure 4.

\section{PCR results}

The results of PCR confirmed the expression of specific osteocyte genes including those for alkaline phosphatase, osteocalcin, and osteopontin (Fig. 5) from bone marrow mesenchymal cells differentiated into osteocytes.

Macroscopic radiographic images

The results of radiography showed that the rate of osteogenesis in the non-nicotine group was much higher than that in the nicotine group and the level of this density was higher in the group with differentiated bone marrow. This issue was completely true for the nicotine group. The self-repair was obviously evident in the control group without any cell transplantation compared to the nicotine group (Fig. 6).

\section{Microscopic histopathologic images}

The results of histologic staining showed that the rate of osteogenesis and bone formation in the canal was more pronounced in the non-nicotine group than in the nicotine group. As shown in

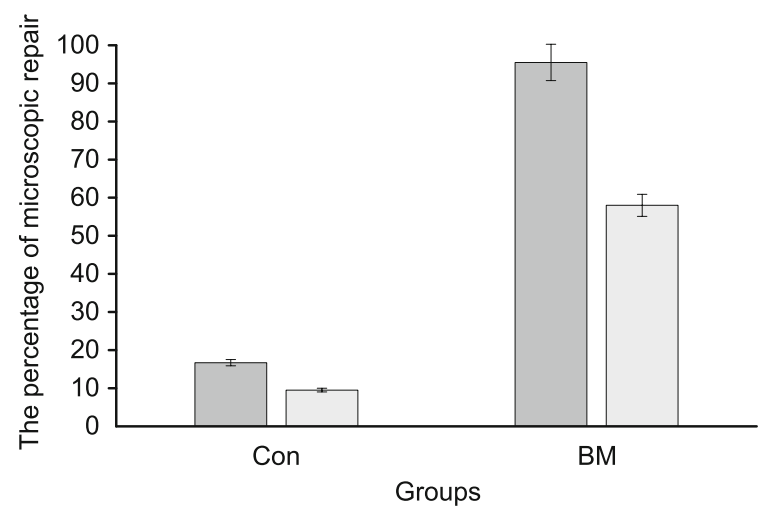

$\square$ Without nicotine $\square$ Nicotine

Fig. 8. The percentage of microscopic repair based on new bone formation after 4 weeks. CON: control, BM: differentiated osteocytes of BMSCs.
Figure 7, the level of regular bone formation in the group differentiated with BMSCs was higher and more intensive than in other groups. On the other hand, in the control group, the process of osteogenesis toward the center and observed in the margin of fracture was also more intensive than in the nicotine control group (Fig. 7).

When comparing nicotine and non-nicotine groups, the regular and continuous bone formation in the non-nicotine group differentiated with BMSCs was more distinct than in the nicotine group in the same situation. The microscopic observations shown in Figure 8 are based on the average repair percentage in the fractured area (samples with severe fracture were not reported and not entered in the percentage determination).

\section{Discussion}

The bone injury is one of the most common causes of morbidity and disability in elderly patients and leads to a decline in general health and quality of life. It has been estimated that every year two million people in the United States suffer from bone fractures due to osteoporosis $(24,25)$. Today, restorative medicine is divided into two parts, namely cell therapy and tissue engineering. Tissue engineering is one of the subjects that can solve the crisis of tissue fracture or the problem with the shortage of organs for transplant. The cells, scaffolds and growth factors are the three major components of tissue engineering. The cells must synthesize the background material of the new tissue, the scaffold provides a suitable environment for the survival and more efficient cell function, and growth factors facilitate cellular progression to revive the new tissue. Despite several studies conducted in order to reconstruct various tissues, there are still outstanding issues such as selection of cellular sources, construction of scaffolds, cell culture, culture media, mechanical properties of cell-scaffold and appropriate animal models in this process. Therefore, the major challenges are those pertinent to cell technology, technology of structure, and attachment of designed structures in the living system $(4,5,26,27)$.

In this research, mesenchymal stem cells were isolated from the rat bone and identified by different tests such as adhesiveness, flow cytometry, differentiation of adipocytes and osteocytes by specific stains, and expression of the desired genes by PCR. The fundamentality of cells was proved and the cells were then stored for the next steps. The cells extracted from each group were differentiated into osteocytes (the third subculture cells, which were placed in osteogenesis differentiation media for 3 weeks underwent morphological changes. They got denser in some places. As a result of staining, the extracellular material in the osteocyte differentiation culture turned red). The cells were then assembled with the prepared collagen to be transferred into modeled and non-modeled animals. In this regard, in a study by Nather and colleagues, autologous mesenchymal stem cell transplantation was used to repair the femoral bone fracture in rabbits. As a result of following allograft transplantation in this study, the bone repair improved and there was an increase in osteocytes in the diaphyseal region (28). The study of Kon and colleagues was focused on bones of large animal models. They evaluated and compared healthy bones with 
damaged bones to which the cells or cells along with the scaffold were transplanted. Two weeks after the cell transplantation, the experimental bones were similar to the control bones and almost completely repaired. A similar result was obtained in sheep eight weeks after transplantation (29). In the study by Caplen et al, it was shown that MSC graft on collagen gel in rabbits with bone and cartilage lesions formed bone and cartilage in the damaged area, but the composed tissue formed in this site was significantly different from the normal tissue in terms of mechanical properties and the tissue was lost within 24 weeks (5). Meinel et al, showed that after transplantation of cells ( 5 weeks), along with trabecular wire mesh scaffold in mice with skull fractures, the number of bone trabeculae in this group exceeded those in the scaffold and control groups (30). The results of the study of Stockman et al are another example worth mentioning. The latter authors seeded ex vivo cultivated autologous mesenchymal stem/progenitor cells on a collagen scaffold, which they then added to calvarial bone defects in pigs. Upon histological evaluations 30 days after transplantation, there was no significant increase in bone calcium content in the experimental group as compared to the control group which only received collagen (31).

In present study, two main groups were studied, namely nicotine and non-nicotine models. For each major group, a control group was also considered. The differentiated osteocytes were obtained from bone marrow and the cells were transferred to the lesions according to the grouping.

After 4 weeks, radiography results showed that the rate of osteogenesis in the non-nicotine group was much higher than in the nicotine group while the newly formed bone in the group that received differentiated cells from bone marrow was denser compared to the group without nicotine. On the other hand, the results of histopathologic staining showed that osteogenesis and bone formation in the non-nicotine group was higher than in the nicotine group. The rate of regular bone formation in the group that received differentiated cells from bone marrow was higher as well. In the control groups, the process of osteogenesis toward the center and observed in the margin of fracture was more intensive than in the nicotine control group.

\section{Conclusion}

Autologous transplantation of differentiated osteocytes of BMSCs in rats with a bone fracture can accelerate the recovery of the bone. Meanwhile, transplantation of autologous differentiated osteocytes of BMSCs has positive effects on bone fracture repair.

\section{References}

1. Rezaei F, Kaka G, Sadraie SH, Jalali H. Effects of Bone Marrow Stromal Cell Transplantation on Repair of Bone Defect in Rats. Trauma Mon 2018; 23 (2): e13701.

2. Karami A, Tebyanian H, Goodarzi V, Shiri S. Planarians: an in vivo model for regenerative medicine. Int J Stem Cells 2015; 8 (2): 128-133.

3. Aggarwal S, Pittenger MF. Human mesenchymal stem cells modulate allogeneic immune cell responses. Blood 2005; 105 (4): 1815-1822.
4. Bartholomew A, Sturgeon C, Siatskas M, Ferrer K, McIntosh K, Patil S et al. Mesenchymal stem cells suppress lymphocyte proliferation in vitro and prolong skin graft survival in vivo. Exp Hematol 2002; 30 (1): 42-48.

5. Caplan AI, Dennis JE. Mesenchymal stem cells as trophic mediators. J Cell Biochem 2006; 98 (5): 1076-1084.

6. Chen L, Tredget EE, Wu PYG, Wu Y. Paracrine factors of mesenchymal stem cells recruit macrophages and endothelial lineage cells and enhance wound healing. PloS one 2008; 3 (4): e1886.

7. Chen Y, Shao JZ, Xiang LX, Dong XJ, Zhang GR. Mesenchymal stem cells: a promising candidate in regenerative medicine. Internat J Biochem Cell Biol 2008; 40 (5): 815-820.

8. Jorgensen C, Gordeladze J, Noel D. Tissue engineering through autologous mesenchymal stem cells. Curr Opin Biotechnol 2004; 15 (5): 406-410.

9. Bordignon C, Carlo-Stella C, Colombo MP, De Vincentiis A, Lanata $\mathbf{L}$, Lemoli RM et al. Cell therapy: achievements and perspectives. Haematologica 1999; 84 (12): 1110-1149.

10. Davis-Sproul JM, Harris MP, Davidson NE, Kobrin BJ, Jaffee EM, Emens LA. Cost-effective manufacture of an allogeneic GM-CSFsecreting breast tumor vaccine in an academic cGMP facility. Cytotherapy 2005; 7 (1): 46-56.

11. Morrison SJ, Shah NM, Anderson DJ. Regulatory mechanisms review in stem cell biology. Cell 1997; 88: 287-98.

12. Augello A, De Bari C. The regulation of differentiation in mesenchymal stem cells. Human Gene Ther 2010; 21 (10): 1226-1238.

13. Pittenger MF, Mackay AM, Beck SC, Jaiswal RK, Douglas R, Mosca JD et al. Multilineage potential of adult human mesenchymal stem cells. Science 1999; 284 (5411): 143-147.

14. Li H, Zuo S, He Z, Yang Y, Pasha Z, Wang Y et al. Paracrine factors released by GATA-4 overexpressed mesenchymal stem cells increase angiogenesis and cell survival. Amer J Physiol Heart Circ Physiol 2010; 299 (6): H1772-H1781.

15. Payne TR, Oshima H, Okada M, Momoi N, Tobita K, Keller BB et al. A relationship between vascular endothelial growth factor, angiogenesis, and cardiac repair after muscle stem cell transplantation into ischemic hearts. J Amer Coll Cardiol 2007; 50 (17): 1677-1684.

16. Babavalian H, Latifi AM, Shokrgozar MA, Bonakdar S, Tebyanian H, Shakeri F. Cloning and expression of recombinant human plateletderived growth factor-BB in Pichia Pink. Cell Mol Biol (Noisy-le-grand) 2016; 62 (8): 45-51.

17. Genovese JA, Spadaccio C, Rivello HG, Toyoda Y, Patel AN. Electrostimulated bone marrow human mesenchymal stem cells produce follistatin. Cytotherapy 2009; 11 (4): 48-56.

18. Zolfaghari D, Tebyanian H, Soufdoost RS, Emamgholi A, Barkhordari A, Herfedoost GR et al. Modified PLGA nanofibers as a nerve regenerator with Schwann cells. Cell Mol Biol (Noisy-le-grand) 2018; 64 (14): 66-71.

19. Taherian A, Fazilati M, Moghadam AT, H T. Optimization of purification procedure for horse $\mathrm{F}\left(\mathrm{ab}^{\prime}\right) 2$ antivenom against Androctonus crassicauda (Scorpion) venom. Trop J Pharm Res 2018; 17 (3): 409-414.

20. Tebyanian H, Mirhosseiny SH, Kheirkhah B, Hassanshahian M. Isolation and Identification of Mycoplasma synoviae From Suspected Ostriches by Polymerase Chain Reaction, in Kerman Province, Iran. Jundishapur J Microbiol 2014; 7 (9): e19262. 


$$
\text { 434-442 }
$$

21. Tebyanian H, Karami A, Motavallian E, Aslani J, Samadikuchaksaraei A, Arjmand B et al. Histologic analyses of different concentrations of TritonX-100 and Sodium dodecyl sulfate detergent in lung decellularization. Cell Mol Biol (Noisy-le-grand) 2017; 63 (7): 46-51.

22. Tebyanian H, Karami A, Motavallian E, Aslani J, Samadikuchaksaraei A, Arjmand B et al. A Comparative Study of Rat Lung Decellularization by Chemical Detergents for Lung Tissue Engineering. Open Access Maced J Med Sci 2017; 5 (7): 859-865.

23. Tebyanian H, Karami A, Motavallian E, Samadikuchaksaraei A, Arjmand B, Nourani MR. Rat lung decellularization using chemical detergents for lung tissue engineering. Biotech Histochem 2018: 1-9.

24. Kern S, Eichler H, Stoeve J, Klüter H, Bieback K. Comparative analysis of mesenchymal stem cells from bone marrow, umbilical cord blood, or adipose tissue. Stem cells 2006; 24 (5): 1294-1301.

25. Majumdar MK, Thiede MA, Mosca JD, Moorman M, Gerson SL. Phenotypic and functional comparison of cultures of marrow-derived mesenchymal stem cells (MSCs) and stromal cells. J Cell Physiol 1998; 1 (1): 57-66.

26. Li H, Fu X, Ouyang Y, Cai C, Wang J, Sun T. Adult bone-marrowderived mesenchymal stem cells contribute to wound healing of skin appendages. Cell Tissue Res 2006; 326 (3): 725-736.
27. Xu W, Hu R, Fan E, Han D. Adipose-derived mesenchymal stem cells in collagen - hyaluronic acid gel composite scaffolds for vocal fold regeneration. Ann Otol Rhinol Laryngol 2011; 120 (2): 123-130.

28. Nather A, David V, Teng JWH, Lee CW, Pereira BP. Effect of autologous mesenchymal stem cells on biological healing of allografts in critical-sized tibial defects simulated in adult rabbits. Ann Acad Med Singapore 2010; 39 (8): 599.

29. Kon E, Muraglia A, Corsi A, Bianco P, Marcacci M, Martin I et al. Autologous bone marrow stromal cells loaded onto porous hydroxyapatite ceramic accelerate bone repair in critical-size defects of sheep long bones. J Biomed Material Res 2000; 49 (3): 328-337.

30. Meinel L, Fajardo R, Hofmann S, Langer R, Chen J, Snyder B et al. Silk implants for the healing of critical size bone defects. Bone 2005; 37 (5): 688-698.

31. Stockmann P, Park J, Von Wilmowsky C, Nkenke E, Felszeghy E, Dehner JF et al. Guided bone regeneration in pig calvarial bone defects using autologous mesenchymal stem/progenitor cells - a comparison of different tissue sources. J Cranio-Maxillofac Surg 2012; 40 (4): 310-320.

Received January 8, 2019. Accepted March 12, 2019. 